\title{
BMJ
}

\section{Investigation of growth, development, and factors associated with injury in elite schoolboy footballers: prospective study}

\author{
Amanda Johnson, senior academy physiotherapist, ${ }^{1}$ Patrick Joseph Doherty, chair of rehabilitation, ${ }^{2}$ \\ Anthony Freemont, professor of osteoarticular pathology ${ }^{3}$
}

${ }^{1}$ Manchester United Football Club, Trafford Training Centre, Carrington, Manchester M31 4BH ${ }^{2}$ York St John University, York 3University of Manchester. Manchester

Correspondence to: A Johnson mandy.johnson@manutd.co.uk

Cite this as: BMJ 2009;338:b490 doi:10.1136/bmj.b490

\section{ABSTRACT}

Objective To investigate the differences between skeletal and chronological age and to assess the role of maturity status, anthropometric data, and football related variables in explaining injury statistics in elite schoolboy footballers.

Design Prospective study of injuries in schoolboy footballers according to skeletal age.

Setting Premier league football club in England.

Participants 292 schoolboy players (age 9-16) registered at the club

Interventions Annual x ray film of hand or wrist.

Main outcome measures Data on injury 2001-7. Skeletal age determined with the Fels method. Skeletal age of more than one year above chronological age was classified as an early maturer, within one year as a normal maturer, and more than one year below normal as a late maturer. Injury and hours of training and rates of exposure to match play. Results Over six years 476 injuries were reported. The mean chronological age (11.74 (SD 2.35) years) and skeletal age defined by $x$ ray picture (12.08 (SD 3.14) years) showed a significant mean difference of -0.344 (95\% confidence interval -0.490 to -0.198 ; $t=-4.64$, $\mathrm{df}=280$ ). Analysis of covariance showed that injury incidents did not differ significantly with maturity status after adjusting for training time, playing time, height, and position played $\left(F=0.3_{2,160}, P=0.73\right)$. General log linear analysis with a Poisson model showed that difference in maturity, playing hours, and training hours collectively explained $48 \%$ of the variance in injury incidents. Injury exposure rates differed considerably, with $1.44 / 1000$ hours for training and 10.5/1000 hours for match play. Conclusion Maturity, defined by the difference between chronological age and skeletal age, plus training and playing hours together predict injury in schoolboy footballers. Injury exposure rates were higher for match play than training, which could have implications for targeting preventative interventions by academy staff. The use of skeletal age measurements to establish accurate "windows of opportunity" for training is more appropriate than the commonly used chronological age. Caution is needed when interpreting differences in injury occurrence as the factors that contribute are often complex.

\section{INTRODUCTION}

As financial rewards and obligations grow there is growing pressure to produce elite athletes in professional sport. Club coaching and medical staff are continually looking for the safest and most successful methods to develop talented young players to compete at the highest level. In youth sport, chronological age is the usual method of dividing children into age related training and competitive groups, but between individuals in the same age group this can differ by as much as four years from skeletal age. ${ }^{1}$ Skeletal age might therefore be a more accurate method of identifying critical periods of development rather than chronological age and consequently a more meaningful method to separate players into training groups. Several studies have explored the monitoring of differences between chronological and skeletal age in youth players, ${ }^{12}$ all of which failed to capture the complexity of the situation. For example, all the studies lacked longitudinal data and some ${ }^{2}$ lacked cross sectional data.

The general consensus seems to be that 10000 hours of directed and organised coaching over a period of 10 years are needed to reach the highest level in any sport. ${ }^{3-5}$ There are specific periods of development where accelerated adaptation to training takes place that maximises the potential of an athlete, ${ }^{67}$ and the ability to identify these periods is constantly being sought. The ability to determine the likelihood and extent of injury during the development periods of immature elite athletes has been at the forefront of preventive medicine for many years, but few studies have been carried out on elite youth football players. ${ }^{8-10}$

Skeletal age is said to be the most accurate method of assessing biological maturity. ${ }^{1211}$ It can be carried out on boys of all age groups and does not rely on the assessment of sexual characteristics, which change during puberty. Assessing skeletal age, either by noninvasive or invasive measures, can give the coach and medical staff an accurate indication of the stage of maturity an athlete has reached. It can show whether the athlete is an early or late developer, which can be an important factor when determining long term 
Table 1|Number of players by age group over six seasons

\begin{tabular}{|c|c|c|c|c|c|c|}
\hline Age group & $2001-2$ & $2002-3$ & $2003-4$ & 2004-5 & $2005-6$ & 2006-7 \\
\hline Under 9s & 15 & 29 & 21 & 23 & 21 & 25 \\
\hline Under $10 \mathrm{~s}$ & 12 & 15 & 27 & 19 & 24 & 24 \\
\hline Under 11s & 11 & 11 & 16 & 24 & 17 & 17 \\
\hline Under $12 \mathrm{~s}$ & 12 & 19 & 18 & 19 & 22 & 19 \\
\hline Under 13s & 14 & 14 & 15 & 13 & 18 & 17 \\
\hline Under 14s & 12 & 14 & 16 & 12 & 16 & 17 \\
\hline Under 15s & 3 & 16 & 17 & 11 & 13 & 13 \\
\hline Under $16 \mathrm{~s}$ & 19 & 3 & 14 & 14 & 10 & 12 \\
\hline Total & 98 & 121 & 144 & 135 & 141 & 144 \\
\hline
\end{tabular}

development plans and ensuring the application of the most appropriate intensity and training protocols. ${ }^{11}$

We examined the relation between chronological age, skeletal age, and injury in elite youth footballers at Manchester United Football Club (MUFC) Academy.

\section{METHODS}

This prospective study entailed repeated measurements over the six years 2001-7. The participants were boys aged 9-16 years from the academy. Participation was voluntary, and both the players and their parents or guardians completed informed consent forms for all aspects of the study.

All the players had been recruited to the club via a scouting network. Once accepted into the club, they completed a medical questionnaire and underwent basic medical screening to ensure there were no predisposing factors that might prevent full involvement in the training and games programme. All consenting players underwent a basic radiograph of the left wrist, which was repeated on an annual basis. Medical staff at the club maintained computerised confidential medical records for each player. The $\mathrm{x}$ ray investigations were undertaken at the clinical radiology department of Manchester University.

We collected data regarding injury, skeletal age, training, and playing hours for every player for the period of time he spent at the academy. We used the most common method to determine skeletal agetraditionally a plain $\mathrm{x}$ ray film of the left hand and wrist. $^{12}{ }^{13}$ There is minimal exposure to radiation, about $0.00017 \mathrm{mSv},{ }^{14}{ }^{15}$ which is the equivalent to about one hour of background radiation in a city centre such as Manchester. The wrist or hand is a convenient area to examine, although other joints such as the hip, knee, ankle, and foot have been used. ${ }^{13} 16$

We determined skeletal age using the Fels method, which uses a bone by bone comparison with the addition of ratios between epiphyses and diaphyses. ${ }^{11718}$ This method is based on a sample population from a mixed socioeconomic group from an area around Yellow Springs in Ohio, United States. The Lifespan Health Research Centre (formally the FELs Institute) verified the researcher's accuracy and competence and the academy used the criteria established by the institute. In our study the intraclass correlation coefficient for the reliability of the Fels measurement was 0.998 (95\% confidence interval 0.996 to 0.999$)$. We classified maturity status into three categories: early, normal, or late. Early and late maturers were classified as such if their skeletal age was more than a year older or younger, respectively, than their chronological age. Normal maturers were those with a skeletal age within one year of their chronological age.

\section{Statistical analysis}

We used a paired $t$ test for differences between chronological and skeletal age and analysis of covariance for the differences between maturity status and injury incidents. To determine factors that predicted injury we used general log linear analysis in a Poisson model on mean data over the six seasons.

\section{RESULTS}

Over the study period of six years, 292 players took part (all of the available boys) with an average of 130 players across all age groups each season (table 1). The players were aged 9-16, with an average chronological age of 11.74 (SD 2.35). The average dropout rate per season was $21.3 \%$. Table 2 shows the number of players represented for consecutive years.

There were 476 injuries across all the age groups. Of these, 244 occurred during training and 169 during match play, which equated to 2.23 injuries each player per 1000 hours of total exposure to training and match play or 1.44 injuries per 1000 hours training compared with 10.5 injuries per 1000 hours in match play. The other injuries (63) were not related to playing football but occurred either in physical education lessons at school or during play with friends. We did not include these injuries in our study. The figures equate to an average of 79.33 injuries per season across all age

$\overline{\text { Table } 2 \mid \text { Number of players in consecutive years at academy }}$ No of consecutive years in academy No of players

\begin{tabular}{ll}
6 & 12 \\
\hline 5 & 25 \\
\hline 4 & 33 \\
\hline 3 & 55 \\
\hline 2 & 72 \\
\hline 1 & 85
\end{tabular}




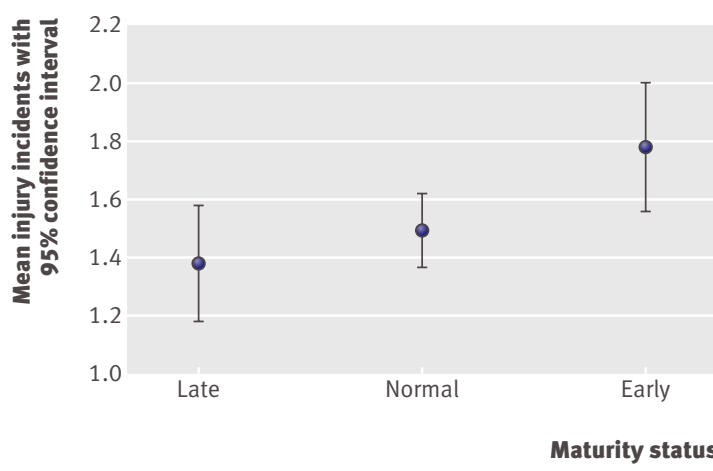

Injury incident differences between maturity status

groups. The average number of days lost per season was 1630.8 , which is an average of 12.5 injury days per player per season. Boys aged under 14 were the most vulnerable, with overuse injuries being more common than direct or indirect trauma. Soft tissue injuries were the most common, with the knee joint being the most commonly injured.

Most $(n=282)$ players underwent $x$ ray examination, which was fewer than the number in the injury analysis because of lack of consent for this part of the study or unavailability at the time the $\mathrm{x}$ ray pictures were taken. Some 85 players had at least one $\mathrm{x}$ ray examination, and 12 players had six consecutive $\mathrm{x}$ ray pictures over the study period.

The mean $\mathrm{x}$ ray defined skeletal age was 12.08 (SD 3.14) compared with a mean chronological age of 11.74 (SD 2.35), and only two thirds of players were shown to be within the normal maturity category. Paired $t$ tests showed significant mean differences $(-0.34$ (SD 1.2) $95 \%$ confidence interval -0.490 to $-0.198 ; t=-4.64$, $\mathrm{df}=280, \mathrm{P}<0.05)$. This indicates that the Fels method overestimates the bone age compared with the chronological age.

We tested the differences in injury incidents associated with maturity status (fig 1) for significance using analysis of variance with covariate analysis of mean playing time, mean training time, mean height, and position played. The analysis showed that the injury incidents did not differ significantly between categories of maturity status when we adjusted for these variables ( $\left.F=0.3_{2,160}, \mathrm{P}=0.73\right)$. The position played, foot dominance, or average height gain were also not determinants of injury occurrence.

We used general log linear analysis in a Poisson model on mean data over the six seasons (table 3), with mean injury occurrence as the main factor and the accepted exploratory variables of mean training time, mean match play time, and mean difference in maturity (chronological minus skeletal age). All three exploratory variables were significantly associated $(\mathrm{P}<0.05)$ with injury occurrence ( $\mathrm{t}$ ratio $=-2.03$ for playing hours, 3.84 for training hours, and -2.65 for maturity status (chronological minus skeletal age)). The percentage of variance explained by the combined model was high at $\mathrm{R}^{2}=48 \%(\mathrm{t}$ ratio $=-4.36, \mathrm{P}<0.001)$.

\section{DISCUSSION}

Maturity, defined by the difference between chronological age and skeletal age, plus training and playing hours together can predict injury in schoolboy footballers. In this study of elite schoolboy footballers, rates of injury were higher for match play than training, which could have implications for targeting preventative interventions by academy staff. The use of measurements of skeletal age to establish accurate "windows of opportunity" that ensure a better alignment with the planned training programmes of age related training and competitive groups is more appropriate than the commonly used chronological age. Caution is needed when interpreting differences in injury occurrence as the factors that contribute are often complex.

The data gathered over six years were sufficient in quality and volume to enable comparative and predictive analysis to verify or refute results of previous studies. We were also able to investigate the relation between injury occurrence, anthropometric, and football related variables. Previous studies that assessed the impact of skeletal maturity in young footballers were limited in their approach in the method used to assess maturity, the length of the study, or the size or age range of the cohort. ${ }^{1}$ We used a prospective approach across a wide age range and a validated method to assess skeletal age.

With reference to defining injury incidents in terms of maturity status, we identified a potential difference in favour of early maturers, who had more injuries than late or normal maturers. This has been reported in previous research in youth football, suggesting that maturity could be the defining characteristic. When we controlled for potential confounding variables (such as mean playing/training time and position played) the differences in incidents were no longer significant. Therefore a degree of caution is required in using categorical variables for instances such as maturity status to infer difference in injury incidents when clearly other factors could at the same time play a part in explaining such differences.

The literature regarding long term development of athletes highlights the concept of "windows of opportunity," where accelerated adaptation can be achieved in response to the correct training regimens. ${ }^{6719} \mathrm{We}$ found that around $30 \%$ of players are either late or early developers, suggesting that many players undergoing training in age defined groups might not benefit optimally from prescribed training regimens. With

Table 3 | Descriptive statistics for 174 boys over six years used in regression analysis

\begin{tabular}{lccc} 
& Minimum & Maximum & Mean (SD) \\
\hline Maturity difference $^{*}$ & -2.82 & 3.06 & $0.50(1.28)$ \\
\hline Playing hours & 0 & 40 & $19.09(6.84)$ \\
\hline Training hours & 32.25 & 365 & $202.27(66.51)$ \\
\hline Injury incidents & 1 & 4 & $1.58(0.71)$ \\
\hline
\end{tabular}

${ }^{\star}$ Chronological age minus skeletal age. 


\section{WHAT IS ALREADY KNOWN ON THIS TOPIC}

The level of evidence underpinning injury statistics and preventive interventions is weak

Uncertainty exists in defining the extent of the relation between injury and maturity status

Rates of exposure to match play determine incidence of injury more than rates of exposure to training

\section{WHAT THIS STUDY ADDS}

Maturity status plus match play and training hours together predict injury in schoolboy footballers

Rate of exposure to match play was associated with a greater incidence of injury than rates of exposure to training

Only two thirds of players were shown to be within the normal maturity category

Injury trends are complex and often multifactorial

the large variability of skeletal age we identified within each individual age group (under 9s up to under 16s) it would be almost impossible for a coach to plan a training regimen that would benefit all the players in each age group. In this context, to maximise the effective use of the window of opportunity it might be more appropriate to group players by skeletal rather than chronological age.

Previous studies have shown that there was a higher incidence of injury during match play rather than during training, ${ }^{9}$ and this was shown to be the case in this study.

Contributors: AJ was the principal investigator and was involved with study design, recruitment, analysis, and write up. PJD took part in study design, analysis, and write up. AF designed and wrote up the study and is guarantor.

Funding: The study was funded by Manchester United Football Club. Competing interests: None declared.

Ethical approval: This study was approved by Manchester University ethics committee (No 05099) and informed consent was given by parents and boys.
1 Malina RM, Pena Reyes ME, Eisenmann JC, Horta L, Rodrigues J, Miller R. Height, mass and skeletal maturity of elite Portuguese soccer players aged 11-16 years. J Sports Sci 2000;18:685-93.

2 Le Gall F, Carling C, Reilly T. Skeletal age and injury in elite youth football. Scand J Med Sci Sports 2006;17:564-72.

3 Ericsson KA, Krampe RT, Tesche-Roma C. The role of deliberate practice in the acquisition of expert performance. Psychol Rev 1993;100:363-406.

4 Ericsson KA, Charness N. Expert performance: its structure and acquisition. Am Psychol 1994; 49:725-47.

5 Baker J, Horton S, Robertson-Wilson J, Wall M. Nurturing sport expertise: factors influencing the development of elite athletes. J Sports Sci Med 203;2:1-9.

6 Bayli I, Hamilton A. Long-term athlete development: trainability in childhood and adolescence: windows of opportunity, optional trainability. Victoria, British Colombia: National Coaching Institute and Advanced Training and Performance, 2004:8.

7 Stafford I. Coaching for long-term athlete development to improve participation and performance in sport. Leeds: National Coaching Foundation, 2005.

8 Deehan DJ, Bell K, McCaskie AW. Adolescent musculoskeletal injuries in a football academy. J Bone Joint Surg Br 2007;89;5-8.

9 Le Gall F, Carling C, Reilly T, Vandewalle H, Church J, Rochcongar P. Incidence of injuries in elite French youth soccer players: a 10-season study. Am J Sports Med 2006;34:928-38.

10 Price RJ, Hawkins RD, Hulse MA, Hodson A. The Football Association medical research programme: an audit of injuries in academy youth football. Br/Sports Med 2004;38:466-71.

11 Malina RM, Chamorro M, Serratosa L, Morate F. TW3 and Fels skeletal ages in elite youth soccer players. Ann Hum Biol 2007;34:265-72.

12 Malina RM, Bouchard C, Bar-Or O. Biological maturation: concepts and assessment. In: Growth maturation and physical activity. 2nd ed. Leeds: Human Kinetics Europe, 2004.

13 Aicardi G, Vignolo M, Milani S, Naselli A, Magliano P, Garzia P. Assessment of skeletal maturity of the hand-wrist and knee: $A$ comparison among methods. Am J Hum Biol 2000;12:610-5.

14 Blake G. Radiation protection-doses and legislation. In: Ring F, ed. Fundamentals of bone densitometry. 2nd ed. Bath: National Osteoporosis Society, 1998.

15 Huda WaG, NA. Radiation dosimetry for extremity radiographs. Health Physics 1998;75:492-9.

16 Castriota-Scanderbeg A, De Micheli V. Ultrasound of femoral head cartilage: a new method of assessing bone age. Skeletal Radiol 1995;24:197-200.

17 Gilli G. The assessment of skeletal maturation. Horm Res 1996;45(suppl 2):49-52.

18 Roche AF, Chumlea WC, Thissen D. Assessing skeletal maturity of the hand-wrist: Fels method. Springfield, IL: Charles C Thomas, 1988.

19 Stratton G, Reilly T, Williams AM, Richardson D. Youth soccer. Science to performance. Abingdon: Routledge, 2004.

Accepted: 12 November 2008 